\title{
Field Experience: Experiential Learning as Complementary to the Conceptual Learning for International Students in a Graduate Teacher Education Program
}

\author{
Oluwatoyin Adenike Akinde ${ }^{1}$, Diane $\operatorname{Harr}^{1} \&$ Phyllis Burger ${ }^{1}$ \\ ${ }^{1}$ Concordia University - St. Paul, College of Education, Department of Graduate Teacher Education, USA \\ Correspondence: Oluwatoyin Akinde, Concordia University - St. Paul, 1282 Concordia Avenue St. Paul MN 55104, \\ USA
}

Received: July 12, 2017

Accepted: August 3, 2017

Online Published: August 11, 2017

doi:10.5430/ijhe.v6n4p137

URL: https://doi.org/10.5430/ijhe.v6n4p137

\begin{abstract}
This study examined the value of field experience as a component of study for international students in a Graduate Teacher Education program at a Midwestern liberal arts university. The purpose of the field experience was to provide a contextual basis for student learning. The espoused research method included a quantitative component via survey and qualitative data, through a focus group interview and participants' field notes. As a result, there is evidence to suggest that the field experience program, as a component of the graduate education program for international students was valuable. Participants described it as being relevant and real. As evident from the field notes, participants reflected on the opportunity for cross-cultural application of their learning, while emphasizing that the learning was palpable and reinforced their conceptual learning. Through the field experience program, participants reported that they gained in-depth insight on leadership and classroom instruction; therefore, they were able to improve their craft as educational leaders. Moreover, evidence from this study also suggests that participants were prepared to approach meaningful educational reform upon returning to their homeland, in Saudi Arabia.
\end{abstract}

Keywords: Field experience, Experiential learning, Global learning, International Students, Graduate teacher education

\section{Introduction}

The purpose of this study was to assess the value of field experience for the international students from Saudi Arabia. The field experience is a part of the graduate studies in educational leadership at a Midwestern liberal arts university in the United States. The intent was to determine the degree to which the field experience enhanced students' learning. Through this study, the value of the experience was evaluated from the perspectives of the students who participated in and completed the field experience.

The assessment included five major constructs, namely (a) the value of experiential learning - that is, the field experience; (b) how well the field experience enlivened conceptual learning from the graduate program in a way that transcended the hermeneutic approach to a practitioner approach; (c) the degree to which the field experience cognate with education and teaching; (d) the degree to which field experience cognate with leadership; and (e) the degree to which students were prepared for work in an academic setting as a result of the field experience.

This study looked at the value of the field experience for international graduate students in the educational leadership program by posing a research question and hypotheses, utilizing a mixed-method approach to the study, collecting and analyzing the data, identifying the delimitations of the study, discussing the findings, and making recommendations for future study. Moreover, this study included a review of the literature through which themes were identified, instruments for the research were designed, and construct validity was established.

This study is significant in the following ways: (a) it contributes to the body of knowledge on the importance of field experience for student at the graduate level; (b) it provides insights about how well students are being prepared for the realities of teaching and leadership; (c) it substantiates the degree to which the field experience enhances the educational leadership program for international students; and (d) it fills a research void given that there are plethora of studies on the impact of field experience, with emphasis on students in general, yet very little attention has been paid to how field experience enhances conceptual learning for international students. 


\section{Review of the Literature}

\subsection{Educational Leadership Graduate Programs}

Educational leadership programs are typically offered at the graduate level - that is, master or doctoral. The program became more prevalent in late 1990 and is mostly geared towards working adults who are already in the teaching profession. Barnett, Basom, Yerkes, and Norris (2000) reported that students in educational leadership studies enter into the program for the purpose of advancement from classroom teaching to an administrative position. Because most administrative positions require that the candidate has prior teaching experience and or holds a teaching license, many students enter into the educational leadership program for career advancement. There is, however, an outlier of people enrolled in the program from other professions. They do so for other reasons including career change or to fulfill a requirement of a position. The participants in this study, namely international students from Saudi Arabia, came to the United States to pursue a master's degree with the goal of career advancement. Notably, the term international student is used synonymously with exchange students (Chow \& Marcus, 2015; Taylor \& Albasri, 2014).

\subsection{International Study}

With the expansion of globalization and study abroad programs, many students come to the United States as exchange students. According to Lin and Yi (1997), the population of international students in the United States has grown exponentially and will continue to grow. The international student population in the United States does not represent a monolithic entity as they come from all over the world. One of the reasons that most international students pursue study in the United States is that of internationalization, a sociological concept commonly used to describe cultural exchange. The term internationalization was initially coined in the field of sociology and anthropology. In Smelser (2003), the terms internationalization and globalization are terms that have converged into a meaningful argument on interdisciplinarity, which predates back several decades and made its presence in several business, marketing, and economic-related studies. In recent time, it has been laudably amplified in the field of education as exemplified by Altbach and Knight (2007) and several of their colleagues.

2.2.1 Saudi Arabian students abroad. Under the King Abdul-Aziz scholarship initiative, the United States has seen a dramatic increase in the number of Saudi Arabians entering the United States to pursue higher education both at the undergraduate and graduate level (Taylor \& Albasri, 2014). The scholarship program was an agreement between former U.S. President G. W. Bush and King Abdullah Abdulaziz of Saudi Arabia in 2005. Under the scholarship, students' tuition, books, room, and board, and other incentives are fully paid. The statistics on the programs that most of these exchange students tend to seek after is lacking. Taylor and Albasri reported that "alumni from the program have studied in the world's top universities and they are bringing this knowledge home to help transform their educational system" (para. 47) as well as the economic and political systems. As a goal of the King Abdul-Aziz scholarship, the group of international students in the educational leadership program, who are participants in this study, are provided with field experience opportunities This experience further reinforces learning and provides an experiential basis that can be useful in attempting to pioneer change upon returning to their homeland.

\subsection{Experiential Learning}

In recent times, educators have deliberated about the more efficient approaches to professional preparation for teachers and school administrators. Through this, scholars and faculty in many teacher education programs have entertained the experiential learning school of thought because of its pragmatic nature, which allows students to learn firsthand. Furthermore, because it lends itself to reflective reasoning (Beyer, 1984; Posner, 2005). Scholars across many teaching academies seem to have embraced the dance between experiential and conceptual learning on many different platforms. Miettinen (2000) attempted to bridge this debate, showing a consensus that experiential learning provides a meaningful overlay to conceptual learning. Simply put, conceptual learning is most evident in the classroom through the mastery of text materials (Guthrie, Anderson, Alao, \& Rinehart, 1999) whereas experiential learning transcends the hermeneutic of the discipline to provide the learner with palpable realities to substantiate the prior heuristics of the teaching and leadership craft.

Experiential learning is rooted in the legacies of John Dewey, Kurt Lewin, and Jean Piaget, which were subsumed in Kolb's definition cited in Sternberg and Zhang (2014). Sternberg and Zhang suggested that experiential learning includes four processes in which knowledge is created through the transformation of experience. The process involves (a) concrete experience, (b) abstract conceptualization, (c) reflective observation, and (d) active experimentation. Sternberg and Zhang went on to state that experiential learning, which is inclusive of the four learning processes previously mentioned, provides a holistic model of the learning process and further support the multi-linear model of adult development, which is consistent with how adult people learn (Daudelin, 1997). 
Notably, experiential learning in the field of education has yielded a few approaches, including field experience, practicum, and internship. Each of these approaches, although rooted in the principles of adult learning and emanated from experiential learning, are inherently different but to similar ends. Building on Baird's (1996) illustrations, Practicum as it applies to teachers' training, allows teachers to work alongside a licensed teacher, who supervises and mentors the teacher in training. Field experience, in general, gives the student an opportunity to observe various aspects of school operations. The internship is often longer than practicum and field experience. It may be paid or unpaid internship, which is based on the tenet of students learning in a real-life setting, hence the argument that these varying topologies of experiential learning in teacher preparation inherently yield similar end.

\subsection{Field Experience}

There is a plethora of evidence that shows the importance of field experience for pre-service teachers and potential school administrators. Beyer (1984) asserted that field experience allows new teachers and administrators to examine educational issues. It is also a form of indoctrination into the profession. Scharmann and Cannon (1996) noted that such preparation is profoundly significant. Although field experience may take different shapes, they are inherently philosophically analogous. However, the core competency of focus may differ depending on the institutional goal (Beard, 2007).

Twenty-first-century primary schools face many challenges, including globalization (as evidenced by the growing number of immigrants) and scarcity of resources including funding, which requires teachers to tap into available grants to support classroom initiatives that would advance student learning. These are among many lists of challenges of the $21^{\text {st }}$-century era. Ashton and Newman (2006) posited that neither pedagogy nor andragogy could be the only strategy for occupational training (ergonagy). Field Experience, when planned with some degree of structure, yet with much room for knowledge sharing (heutagogy), allows for critical thinking and reflection.

\subsection{Context of the Study}

Similar to most teacher practicums illustrated by Bain, Ballantyne, Packer, and Mills (1999), the graduate students under study were required to keep a written journal of their field experience, documenting their observations, questions they had, answers they discovered, times and dates of the field experience, grade level under which the field experience took place, and structure of the school, among other things. Notably, this field experience was not intended to and did not lead to, a teaching or administrative licensure. Rather, the purpose of the field experience was to expose the international students, as participants in this study, to the daily realities of teachers, administrator, school operations, and student life during the school day.

The field experience was in three phases, each requiring a minimum of nine hours in a school building under the supervision of a teacher and or one of the school's administrative staff. Each phase had a different focus: (1) Phase 1's emphasis was on school leadership and its compadres', intellectual liberty, and serving a diverse student population; (2) Phase 2's emphasis was on curriculum design, implementation, and its assessment; and (3) Phase 3's emphasis was on lesson planning, evaluation, implementation, and cross-cultural application. At each phase, students were placed in different settings including charter schools, private schools, and Montessori schools. The placements were intentional, in part, to expose students to elementary, middle, and high school settings. Part of the requirement of the field experience required in-class contact hours under the teaching of university professors (one of whom also served as field experience coordinator). The in-class instructional activities were facilitated in a face-to-face modality as a seminar course in which students reported their experience in the field site, shared insights, and produced a reflection and action research paper (heutagogy). Further still, students were required to address how the learning from the field experience could be applied in the context of the school system in Saudi Arabia.

A partnership was initiated between the field site teacher and administrator and the student's university program of study. The on-site teacher oversaw the student's field experience in the classroom. The classroom teacher was at liberty to engage the graduate students in a series of activities including classroom observation, professional learning community meetings, classroom projects, and other instructional activities, in a manner consistent with the principals of ergonagy. Additionally, the on-site teacher scheduled time with the student provided feedback to the students and kept in close contact with the field experience coordinator at the university.

Students' responsibilities included meeting with the field experience coordinator about the field experience site and classroom teacher contact information. Moreover, students made an introductory contact with the classroom teacher and agreed on a time and date when the field experience would commence. Students scheduled subsequent meetings and maintained contact and professional relationships with field sites administrators, classroom teachers, and consortiums. Students' field experience was not limited to classroom observation, classroom projects, and building 
meetings (at the discretion of the classroom teacher), and other instructional activities. Upon completing the required hours in each phase, students exit by meeting with the classroom teacher to gain their professional perspective and feedback. Students documented feedback and key learning in the progress report journal.

The field experience coordinator served as a point of contact between the on-site teacher and the graduate student and worked with field site to establish contact with the administrator and the classroom teacher.

\section{Methodology}

\subsection{Research Question}

The research question was, Did the field experiences enhance the learning experience of international students in the educational leadership program?

\subsection{Research Hypotheses}

The null hypothesis $\left(\mathrm{H}_{0}\right)$ was, Field experiences enhanced the learning experience of international students in the educational leadership program.

The alternate hypothesis $\left(\mathrm{H}_{\mathrm{A}}\right)$ was, Field experiences did not enhance the learning experience of international students in the educational leadership program.

\subsection{Definitional Context for the Study}

Several terms meant different things depending on the field and context. Hence, this section provides an illustration of terms that are being adopted for this study. The terms defined in this section were derived from other studies that were directly or tangentially related to the topic under study.

\subsubsection{Educational leadership program.}

Educational leadership programs have gained much popularity in recent time. There is a growing consensus that educational leadership programs are mostly offered at the graduate level to prepare school administrators and academic practitioners (Jackson \& Kelley, 2002; Young, 2015).

\subsubsection{Field experience.}

Field experience takes many shapes in providing students, generally prospective teachers, an opportunity to examine a variety of educational issues from a critical perspective (Beyer, 1984) in such a way that helps students contemplate reflective teaching (Posner, 2005) in so far as the students engage the heuristics from their coursework.

\subsubsection{International students.}

In the United States, international students are students who migrate to the United States to pursue an education (Chow \& Marcus, 2015). Participants in this study, being international students in the educational leadership graduate program, migrated from Saudi Arabia, have earned their undergraduate degree before enrolling in the graduate program.

\subsection{Research Design}

This study takes an explanatory mixed-method approach. It includes both quantitative and qualitative design. The quantitative aspect reports on findings from the Likert scale and binary questionnaire premised on identifying the degree to which students found the field experience valuable regarding strengthening their learning on teaching and leadership. For the qualitative method, students were interviewed in a focus group. Also, participants' field notes (progress report journal) and reflections were taken into consideration, and the themes were highlighted. Both methods are reported separately under the data analysis and result section. The Likert scale and binary questionnaire are also addressed under instrumentation.

\subsection{Population and Sampling}

Student participants were members of graduate cohorts in the education program at a Midwestern liberal arts university campus. The cohort included both international and domestic students. However, only the international students from Saudi Arabia were part of the field experience. This being the first cohort of students participating in the field experience and based on the number of Saudi Arabian students in the cohort, a random sampling would yield a relatively small number of participants. Therefore, the researchers conveniently took the international students from Saudi Arabia as the study population (N). Although students were asked to participate in the study, their participation was not mandatory. Based on participants' voluntary nature of this study, there was a total of 10 participants (n) in the study. 
The researcher sent out an email broadcast to the entire population, to share the goal of the researcher in evaluating the value of the field experience. A total of 11 students responded and attended the informational meeting. Of the 11 students, one opted out, while ten students volunteered to participate in the study. The research procedure was shared, and students were encouraged to ask questions. One student asked about sharing the research findings with the entire Saudi Arabian population, citing the limited number of published research of this kind that pertains to Saudi Arabia. The student was informed that the results would be published at the conclusion of the study, which would make it available in the public domain for anyone interested. The meeting was concluded, with the participants being informed that their names and information would be kept anonymous and would not be shared. They were further encouraged to reach out to the researchers at any time for any question. Hence, the researchers' email addresses were shared with the participants.

Participants were mostly females and one male. Their participation in this study was voluntary. Participants' incentive for participating was the knowledge they would gain from being a part of the study, which they agreed would be beneficial to the advancement of education and research for Saudi Arabia.

\subsection{Instrument}

\subsubsection{Survey questions.}

The survey questions (Appendix A) were constructed based on the five previously stated constructs. The survey was channeled to assess participants' affective domain - that is, the value (Popham, 2000) of the field experience, as experienced by the students. The questions consisted of five main questions with sub strand questions. Four of the questions were binary, True/False questions, and five questions were Likert scale questions with four options.

\subsubsection{Demographic questions.}

The demographic questions (see Appendix B) were comprised of four questions for the participants; being the students that participated in the field experience. The questions pertained to gender, a program of study, age, and years of prior experience in a school setting and where that prior experience took place. The demographic data was administered with the survey, therefore, was completed by the ten students. The purpose of the demographic data collected was to develop context surrounding this study for the sake of replicability.

\subsubsection{Interview questions.}

The interview questions (see Appendix C) were open-ended questions that reinforced and provided greater insights into the survey question. The interview questions included six questions soliciting a reflective response from the students as participants of the study.

\subsubsection{Reliability and Validity of the Instruments}

Rigor is considerably important in conducting academic research. Therefore, the rigor of a research design necessitates a discussion on the validity and reliability rating of the research instrument. To state this precisely, validity refers to the truthfulness, while reliability is concerned with consistency (Fraenkel, Wallen, \& Hyun, 1993).

As previously stated, this study espoused a mixed-method design, including a survey questionnaire and interview questions. Validity was established based on the following processes: Identifying the research themes, which included five constructs based on evidence from several literature reviews. The interview questions, which included five questions, were given to two experts in the field of education: one field experience supervisor and one education professor, who has extensive experience with international students. These two individuals served as peer-review experts, gave feedback about the degree to which the interview questions and survey instrument align with the research question. One of the experts suggested that the term validate as used in the original survey, should be replaced with enliven, which has been revised in the survey. It is important to note that the process of establishing validity, as it applies to this study, preceded the reliability testing of the survey.

The survey questionnaire was sent to international students from various countries who are studying in the United States and have participated in some form of field experience, internship, or practicum through a school in the Midwest; given that, it was a challenge to target a larger number of Saudi Arabian students. The students were identified based on word of mouth from other international students in a close network with the researchers of this study. Also, the international student club and international students' service offices from two Midwestern campuses were contacted to solicit participation in piloting the instrument. Of the returned survey, 31 were completed in its entirety and then used in testing the reliability of the survey instrument, which represents the norm group. The survey, though normed with international students from various countries in the United States, was then adapted for the population under study, namely Saudi Arabian students in the graduate teacher education program. The norm group and the participants were 
considered homogeneous on the basis of migration to the United States, and on the basis of being exchange students, and enrollment in a graduate education degree program.

Cronbach's alpha, which is commonly used in testing instrument's reliability was used. The survey, shown in Appendix A, had five Likert scale questions and four binary scale questions. The Likert scale questions were designed having four options. The Likert scale was converted from letters A-D into numbers, being 1-4. Although the reliability testing of the instrument is considered small scale, based on 31 respondents, Minitab was used to calculate multivariate item analysis of the survey. Likert scale questions, which yielded an alpha, of 0.7132 (see Table 1). This meant that the Likert scale questions are $71 \%$ reliable. The binary questions, on the other hand, included four True/False questions with a Cronbach alpha of 0.7679 (as shown in Table 2). Thus, the binary questions are $76 \%$ reliable. The researchers involved in this study were comfortable with this rating, given that $70 \%$ reliability rating is considered moderate in social science research (Popham, 2000).

Table 1. Cronbach Alpha of the Likert Scale Questions: Item Analysis of 1.1, 2.1, 3.0, 4.0, and 5.0

\begin{tabular}{|c|c|c|c|c|c|}
\hline \multicolumn{6}{|c|}{ Pearson correlation matrix } \\
\hline \multicolumn{2}{|c|}{ Variable 1a } & \multirow[t]{2}{*}{$2 a$} & \multirow[t]{2}{*}{3} & 4 & \\
\hline $2 \mathrm{a}$ & 0.285 & & & & \\
\hline 3 & 0.259 & 0.528 & & & \\
\hline 4 & 0.196 & 0.208 & 0.478 & & \\
\hline 5 & 0.224 & 0.012 & 0.442 & 0.630 & \\
\hline \multicolumn{6}{|c|}{ Item and total statistics } \\
\hline Variable & Total count & Mean & Std dev & & \\
\hline$\overline{1 \mathrm{a}}$ & 31 & 1.2903 & 0.4614 & & \\
\hline $2 \mathrm{a}$ & 31 & 1.4194 & 0.5642 & & \\
\hline 3 & 31 & 1.4194 & 0.6204 & & \\
\hline 4 & 31 & 1.3871 & 0.5584 & & \\
\hline 5 & 31 & 1.4516 & 0.6239 & & \\
\hline Total & 31 & 6.9677 & 1.9405 & & \\
\hline \multicolumn{6}{|c|}{ Cronbach's alpha $=0.7132$} \\
\hline \multicolumn{6}{|c|}{ Omitted item statistics } \\
\hline Variable & Adj. total mean & Adj. total std dev & Item-adj. total corr. & Squared multiple corr. & Cronbach's alpha \\
\hline $1 \mathrm{a}$ & 5.677 & 1.739 & 0.3282 & 0.1302 & 0.7145 \\
\hline $2 \mathrm{a}$ & 5.548 & 1.670 & 0.3492 & 0.3828 & 0.7124 \\
\hline 3 & 5.548 & 1.480 & 0.6489 & 0.4848 & 0.5828 \\
\hline 4 & 5.581 & 1.566 & 0.5731 & 0.4536 & 0.6234 \\
\hline 5 & 5.516 & 1.568 & 0.4694 & 0.4903 & 0.6672 \\
\hline
\end{tabular}


Table 2. Cronbach Alpha of the Binary Scale Questions: Item Analysis of 1b, 1c, 2b, and 2c

\begin{tabular}{|c|c|c|c|c|c|}
\hline \multicolumn{6}{|c|}{ Pearson correlation matrix } \\
\hline \multicolumn{2}{|c|}{ Variable $1 \mathrm{~b}$} & \multirow[t]{2}{*}{$1 \mathrm{c}$} & \multicolumn{2}{|l|}{$2 \mathrm{~b}$} & \\
\hline $1 \mathrm{c}$ & 0.878 & & & & \\
\hline $2 b$ & 0.616 & 0.762 & & & \\
\hline $2 \mathrm{c}$ & 0.022 & 0.183 & 0.392 & & \\
\hline \multicolumn{6}{|c|}{ Item and total statistics } \\
\hline Variable & Total count & Mean & Std dev & & \\
\hline$\overline{1 b}$ & 31 & 1.1290 & 0.3408 & & \\
\hline $1 \mathrm{c}$ & 31 & 1.1613 & 0.3739 & & \\
\hline $2 b$ & 31 & 1.1613 & 0.3739 & & \\
\hline $2 c$ & 31 & 1.2258 & 0.4250 & & \\
\hline Total & 31 & 4.6774 & 1.1658 & & \\
\hline \multicolumn{6}{|c|}{ Cronbach's alpha $=0.7679$} \\
\hline \multicolumn{6}{|c|}{ Omitted item statistics } \\
\hline$\overline{\text { Variable }}$ & Adj. total mean & Adj. total std dev & Item-adj. total corr. & Squared multiple corr. & Cronbach's alpha \\
\hline $1 \mathrm{~b}$ & 3.5484 & 0.9252 & 0.6139 & 0.7908 & 0.6935 \\
\hline $1 \mathrm{c}$ & 3.5161 & 0.8513 & 0.7770 & 0.8500 & 0.5964 \\
\hline $2 b$ & 3.5161 & 0.8513 & 0.7770 & 0.6476 & 0.5964 \\
\hline $2 \mathrm{c}$ & 3.4516 & 0.9946 & 0.2238 & 0.2370 & 0.9000 \\
\hline
\end{tabular}

3.7 Data Collection

The survey instrument was used to collect data about the value of the field experience. With the field experience being three phases, and each requiring a minimum of nine hours, ten consenting students completed the survey at the end of the third phase.

The qualitative aspect of the study took place after students have completed the field experience program. The interview took place as a focus group via WebEx, an online auditory and visual platform. Results of the interviews were documented, recorded, and later transcribed by the researchers.

Students were required to keep a $\log$ for the three phases of the field experience. The log used to take field notes also served as a qualitative instrument through which students as participants could freely document their learning experiences.

The qualitative research study is often concerned with context and gaining a deeper understanding of participants' experience. Therefore, it is not a concern with reliability. However, Brewerton and Millward (2001) invited researchers to think of triangulation as a means to that end. Triangulation, which has many forms, depends on the access to data. Triangulation in this particular study comprised of findings from the survey, the focus group interview, and transcription from students' field notes. These three components provided robust and meaningful conclusions from the results.

\subsection{Delimitation}

This study takes into account a variety of factors. First, it takes into account the background of the students. Therefore, demographic data were gathered from the participants to establish generality among the students under study. Secondly, it factors in the reflective experience of the participants. Therefore, students log of their experience during the field placement were also tracked for themes. Third, and most importantly, this study gathered data on the significance of the field experience in the context of the degree to which it enhanced students' conceptual learning from the educational leadership program. 


\subsection{Limitation}

The primary limitation of this study includes the small sample size, and the use of convenient sampling. Based on having only one male participant, and others being female, the impact of the gender difference relating to the research findings could not be statistically and qualitatively accounted for. Nonetheless, the findings from this study provided new information given the limited research on international students' study, specifically Saudi Arabian students in the United States. It is also a valid assertion to state that this research helps to fill a void for future researchers and the Saudi Arabian government. Understandably, it also reinforced pre-existing study on field experience for teachers.

\section{Findings}

For the interview protocol, four students were interviewed in a focus group. Each participant was given a chance to respond openly to the interview questions (see Appendix C). The field log, which included notes from the participants' field learning, was also brought to bear in the findings reported in this study. The log included a cursory note of the students learning. Because some of the observations were part of the action research paper of the student, it is considered the intellectual property of the student. Therefore, was not used in this paper.

\subsection{Survey Results}

The results of the 10 participants that went through the field experience program is as follow: first, the Likert scale result yielded an alpha of 0.7981 (as shown in Table 3), indicating that the field experience program, when statistically measured using Minitab 16 software, was considered beneficial by the students. Secondly, the binary scale questions could not yield a result, when calculated using Minitab 16, because there was no variability based on all 10 participants reporting true for all the four binary (True/False) questions.

Table 3. Cronbach Alpha of the Likert Scale Results: Item Analysis of 1a, 2a, 3, 4, and 5

\begin{tabular}{|c|c|c|c|c|c|}
\hline \multicolumn{6}{|c|}{ Pearson correlation matrix } \\
\hline \multicolumn{2}{|c|}{ Variable 1a } & \multirow[t]{2}{*}{$2 \mathrm{a}$} & \multirow[t]{2}{*}{3} & 4 & \\
\hline $2 \mathrm{a}$ & -0.389 & & & & \\
\hline 3 & 0.248 & 0.000 & & & \\
\hline 4 & -0.469 & -0.302 & 0.000 & & \\
\hline 5 & -0.017 & -0.234 & 0.000 & 0.188 & \\
\hline \multicolumn{6}{|c|}{ Item and total statistics } \\
\hline Variable & Total count & Mean & Std dev & & \\
\hline$\overline{1 \mathrm{a}}$ & 10 & 3.300 & 0.949 & & \\
\hline $2 \mathrm{a}$ & 10 & 3.800 & 0.422 & & \\
\hline 3 & 10 & 3.000 & 0.471 & & \\
\hline 4 & 10 & 3.600 & 0.699 & & \\
\hline 5 & 10 & 3.700 & 0.675 & & \\
\hline Total & 10 & 17.400 & 1.174 & & \\
\hline \multicolumn{6}{|c|}{ Cronbach's alpha $=-0.7981$} \\
\hline \multicolumn{6}{|c|}{ Omitted item statistics } \\
\hline Variable & Adj. total mean & Adj. total std dev & Item-adj. total corr. & Squared multiple corr. & Cronbach's alpha \\
\hline $1 \mathrm{a}$ & 14.1000 & 1.1005 & -0.34478 & 0.59219 & -0.28030 \\
\hline $2 \mathrm{a}$ & 13.6000 & 1.3499 & -0.46817 & 0.49876 & -0.03388 \\
\hline 3 & 14.4000 & 0.9661 & 0.19926 & 0.13147 & -2.09725 \\
\hline 4 & 13.8000 & 1.2293 & -0.32464 & 0.52910 & -0.32509 \\
\hline 5 & 13.7000 & 0.9487 & -0.04286 & 0.07271 & -1.11532 \\
\hline
\end{tabular}




\subsection{Focus Interview Results}

\subsubsection{Interview Question 1.}

Provide a contextual value of the field experience as you have experienced it.

Participant A said, "The field experience is invaluable. As a future teacher leader, it was so important to go from school to school learning from principals, how to supervise teachers and run a school building as a whole."

Participant B stated, "I gained insights into the big picture, through which I had a lot to take back to my homeland."

Participant $\mathrm{C}$ reported that one of the most valuable learning was about multiple intelligences- "how that is used in making instructional planning and decisions. Before the field experience, the learning about teaching and leadership was somewhat abstract. The field experience brought the learning home for me because I saw, I asked, and I practiced." Furthermore, Participant C said, "My teaching craft is so much more improved."

Participant D stated, "I learned more about teaching and curriculum and instruction." Additionally, Participant D said, "I gained real-life perspectives on how principals run their schools. The field experience gave me an insight into the big picture of educational leadership and meeting the needs of school constituents."

\subsubsection{Interview Question 2.}

Are you better prepared to serve as an educator, a leader, or both as a result of the field experience? If so, why?

Participant A responded emphatically, saying, "Yes," because she now "[has] perspectives on educational leadership so that [she] could support teachers when [she] returns to [her] home country."

Participant B said, "Yes, I learned the intricacies of teaching as a profession, classroom instruction, and school leadership. Therefore, I feel prepared for both leadership and teaching. In fact, I learned from the field experience program that leading is inherently teaching and that what is different is the population of learners."

Participant C said, "Yes," and went on to say that the field experience benefited her so much that she feels she could train teachers when she returns to her homeland. She learned that one leads to influence rather than leading with a loud voice, which is a "shift in paradigm for me." By the same token, she said she also learned that everyone could be a leader, which is a different mindset from where she was before coming to the United States for graduate studies.

Participant D responded emphatically, saying, "Both," and illustrated by saying,

I gained an understanding of how to use research in making decisions in schools, a skill I did not have before. The field experience program included an action research project on specific areas of instruction and administration. The triangulation, which included three components - namely, research, interview, and observation — brought the learning home in a way that made it real and relevant.

\subsubsection{Interview Question 3.}

Did the field experience provide you with the cross-cultural application? If so, what specifically about the field experience gave you a cross-cultural lens that you were able to apply in Saudi Arabia?

Participant A said, Yes, I now have insights into administrating and improving a school, as a result of the learning from the field experience program. In fact, the field learning has lifted me above the ground that I could see the need for change in my home country.

Additionally, it seems that the educational goal in Saudi Arabia and the United States have similar ends, yet there is much improvement necessary when she "[thinks] of the disparity between private and public school system in Saudi Arabia and the need for accountability." Perhaps, the administrating body is far too removed, which is not the case in the United States.

Participant B said, "I learned how to value the learning process of students and the teachers. This gave me some perspectives on the importance of collaboration as a way of carrying everyone along." More importantly, the assignments in the field experience program were very helpful in prodding cross-cultural thinking. From one of the assignment, we were asked to design a lesson, teach it, and ask for feedback. I did mine on teaching elementary level students how to write a letter. When I had to address the cross-cultural piece of the lesson, I had to discuss how the writing of letter starts from the right side in Saudi Arabia. Therefore, that if I were to teach this in Saudi Arabia, I would adjust the lesson to include the type of writing material used in Saudi Arabia.

Participant C said, Yes, I have been exposed to people of many nationalities through the classroom work and the field experience. America is really a salad bowl, and I think this broadened my perspectives on applying learning in Saudi. 
Plus, the assignments in the field experience program intentionally nudge cross-cultural application of the concepts learned. This informed my future goal of being an educational leader when I return home.

Participant D said, "Communication was enhanced for me because the push for cross-cultural analysis of the learning helped me to analyze situations from the Western and the Saudis' perspective. The field experience provided a broader perspective on teaching and learning; it gave me ideas that I would take back to Saudi. Through the field experience, I have learned the value of student differences - that is, differentiation of instruction - and how to foster a morally healthy school environment."

\subsubsection{Interview Question 4.}

What would be different for you had you not participated in the field experience?

Participant A said, "Being in the classroom with the professors and peers prepared me for the field experience because while I was in the school setting, when terms, phrases, and acronyms were used, I had a frame of reference. Moreover, through the field experience, I learned about effective leadership. I saw how the reading and theories are used in an actual school setting. Safe to say that the field experience provided a more palpable learning experience."

Participant B said, "I have truly started to understand education in America." The school system in Saudi Arabia is very different, even when it comes to organizing and structure. In the United States, most schools are coed, but this is not the case in Saudi Arabia. Through the field experience, "I learned about the many constituencies connected to schools, including the Department of Education, as opposed to the Ministry of Education in Saudi Arabia. I also learned how principals actually work effectively and efficiently. The term accountability is more real to me now than in the past; so is leading and managing a school".

Participant $\mathrm{C}$ said, "Field experience gave me lenses to look through. The assignment and classroom work gave me perspectives on policy relating to school policies. However, the field experience provided contextual basis for the conceptual learning."

Participant D said, "It gave a good learning experience. Now, I feel like I am better prepared to engage in school improvement in the homeland. I started the Master of Arts in Education program with some feeling of doubt and uncertainty, which I still have. The difference is that I now know what those concepts mean - how they influence school and the society."

\subsubsection{Interview Question 5.}

Did the field experience help you apply the concepts, theories, and philosophies of education and leadership that you were exposed to in the program? Participant B said, "Absolutely." Participant D said, "Yes."

\section{Participant Demographics}

Participant A had two years of experience teaching in middle school. Participant B had no experience in teaching and was a freelance artist and an entrepreneur. Participant $C$ was a school social worker for 6- to 12-year-old students. Participant D had less than one year of experience in middle school. Two of the participants were between 22-28 years of age, one was between 29-38 years of age, and one was 36 years or above.

\subsection{Field Log}

Participant A.

"I went to a board meeting; I saw how they debate issues about school improvement, budget, and accountability." The principal mandated teachers to stay after school hours to prepare for an open house conference. This is so different! Why is there more than one teacher in the classroom? Teachers are in the building as early as 7 a.m. even though students start arriving at 8:40 a.m.

Participant B.

Teachers involve the parents on student discipline. The principal held a meeting with parents to discuss the change in the curriculum so that they could help them at home. Parents were asked to weigh-in on the curriculum. "I like the lunchroom and how it is organized." Most teachers eat lunch on the same table with their students, which allowed them to bond beyond the classroom. I asked a teacher about this, and he said he caters to the whole child, not just on math or reading."

Participant C.

Teacher applied for a grant to purchase alternative seating so that students can find their comfortable learning position in the classroom. School safety is very important to the school principal. Every adult in the building is trained about 
the safety code and what is expected of them to keep the students safe. Everyone had to read the plan and sign that he or she understands the safety plan. "I saw a lockdown drill; every classroom teacher had their windows closed, displayed a colored paper on the bottom to indicate that all their students are accounted for. The teachers all kept the students calm in the class, during this drill. I thought wow, we need to do this in Saudi Arabia. I saw the principal helping in the classroom and not just [sitting] in his office. He was picking refuse off the lunchroom floor, which is so humbling and interesting."

\section{Participant D.}

Teacher discussed the home visit with the instructional leader of the school. The teacher said she visited the student's house to discuss behavior problem. She said she did not want to wait until the parent-teacher conference because the time allotted is usually short and parents want to discuss the academic things. There was a plan in place for a substitute teacher, so that they know about the building and the expectations. "We do not have substitute teachers in Saudi Arabia. In my country, if a teacher is absent, another teacher will be asked to teach two or more classes simultaneously. I should suggest the use of substitute teacher when I get back to Saudi; it is so good. There was a pep rally; we have something similar in Saudi but not in every school. So I could relate to this, and I see that students and community people like it."

\subsection{Triangulation}

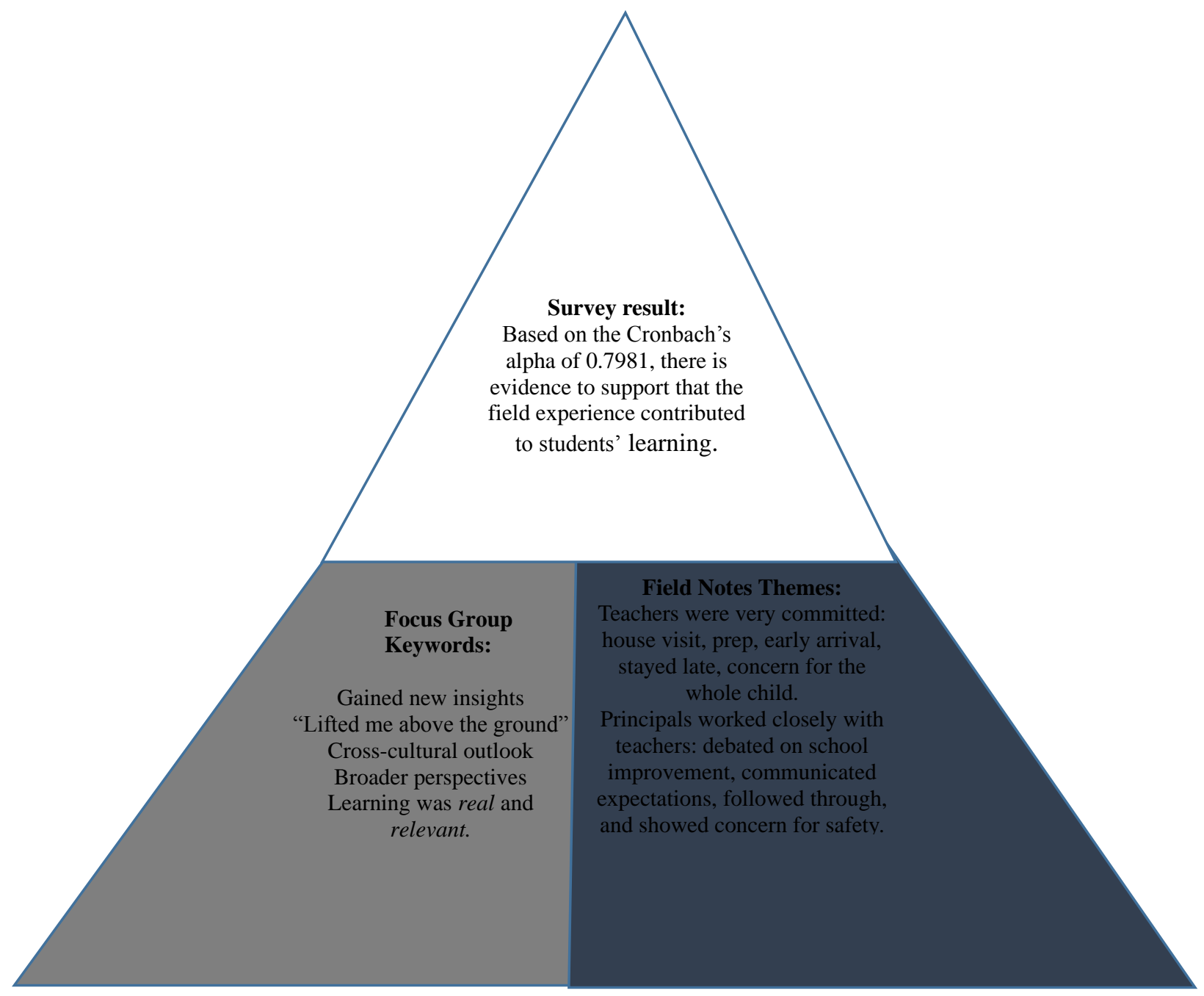

Figure 1. 


\section{Summary}

In light of what is known about the significance of field experience for international graduate students in the education program, there is evidence from this study to suggest that field experience program enhanced the learning experience of international students in the educational leadership program. Based on (a) the Cronbach's alpha of 0.7981 from the survey results of the 10 participants (see Table 3), one can assert that the participants considered the field experience beneficial. Therefore, the null hypothesis $\left(\mathrm{H}_{0}\right)$, which stated that field experience enhanced the learning experience of international students in the educational leadership program, is accepted. (b) From the narrative gathered from the focus group interview and the field log, what remained prominent across the data collection was that the learning was palpable - that is, relevant and real. It was also gathered that the field experience clarified concepts and theories that would have otherwise been left opaque. It brought pragmatism to the preparation of the students' learning of teaching and leading, as reported by the participants. In other words, the participants considered the field experience learning to be valuable. More importantly, from the qualitative data, it was evident that the participants gained insights into what they would change and what they would implement to improve the education of students and school leadership after returning to their homeland.

The implication to Graduate Teacher Education and Educational Leadership preparation programs with international students is that heutagogy and ergonagy as components of the field experience learning can be valuable when combined with andragogy - fostering real and relevant learning, which surpasses conceptual learning.

Although the previously stated results indicate that the field experience is invaluable for international students, it is noteworthy to state that findings from this study could not be generalized because the number of participants is considered small to be statistically significant and because of the use of convenient sampling. Nonetheless, the three espoused data collection was triangulated (see figure 1), that is, confirmative, and provided some degree of substantiation to the findings reported in this study.

\subsection{Recommendation for Future Research}

Based on the statistical result of the reliability rating of the binary questions from the norm group, we recommend omitting variable 2.3 to increase the Cronbach's alpha from 0.7679 to 0.9000 (see Table 2), which will further increase the rating of the research construct on the binary scale questions. Moreover, no such method applies to the Likert scale because the only increase with variable 1.1 is from 0.7132 to 0.7145 (see Table 1), which is not significant.

A plan for follow-up communication with the participants after having returned to their homeland for two to three years was pre-empted, due to several circumstances. Three of the participants cited communication breakdown, the difference in time zone, and technological challenges, as factors that would most likely impede future follow-up. For some of the participants, these researchers will attempt a longitudinal follow-up study to evaluate the participants' experience after some period of employment.

It would be advantageous if future researcher would explore the nature of improvement made to the educational system in Saudi Arabia, as a result of the educational leadership training that exchange students have received.

Finally, future research could carry out another study on the impact and value of field experience program for international students, with a larger sample, using the instrument (see Appendices A-C). Given that the instrument was normed with a small sample size, it would be illuminating to see what the reliability rating report shows with a larger sample.

\section{Acknowledgment}

To the students who participated in this study, thank you. This body of work could not have been completed without your contributions of candid communication. Many thanks to Dr. Ibrahim DeVries and Dr. Johan Dirks for reviewing the instruments for this study. Also, a sincere appreciation to Marjorie Metts for her editorial support.

\section{References}

Altbach, P. G., \& Knight, J. (2007). The internationalization of higher education: Motivations and realities. Journal of Studies in International Education, 11(3/4), 290-305. https://doi.org/10.1177/1028315307303542

Ashton, J., \& Newman, L. (2006). An unfinished symphony: 21st century teacher education using knowledge creating heutagogies. British Journal of Educational Technology,37(6), 825-840. https://doi.org/10.1111/j.1467-8535.2006.00662.x 
Bain, J. D., Ballantyne, R., Packer, J., \& Mills, C. (1999). Using journal writing to enhance student teachers' reflectivity during field experience placements. Teachers and Teaching: Theory and Practice, 5(1), 51-73. http://dx.doi.org/10.1080/1354060990050104

Baird, B. N. (1996). The internship, practicum, and field placement handbook: A guide for the helping professions. Prentice Hall.

Barnett, B. G., Basom, M. R., Yerkes, D. M., \& Norris, C. J. (2000). Cohorts in educational leadership programs: Benefits, difficulties, and the potential for developing school leaders. Educational Administration Quarterly, 36(2), 255-282. https://doi.org/10.1177/0013161X00362005

Beard, D. F. (2007). Assessment of internship experiences and accounting core competencies. Accounting Education: An International Journal, 16(2), 207-220. http://dx.doi.org/10.1080/09639280701234625

Beyer, L. E. (1984). Field experience, ideology, and the development of critical reflectivity. Journal of Teacher Education, 35(3), 36-41. https://doi.org/10.1177/002248718403500308

Brewerton, P. M., \& Millward, L. J. (2001). Organizational research methods: A guide for students and researchers. Sage. https://doi.org/10.4135/9781849209533

Cannon, J. R., \& Scharmann, L. C. (1996). Influence of a cooperative early field experience on preservice elementary teachers' science self - efficacy. Science Education, 80(4), 419-436. https://doi.org/10.1002/(SICI)1098-237X(199607)80:4<419::AID-SCE3>3.0.CO;2-G

Chow, P., \& Marcus, R. (2015). International students in the United States. International Higher Education, (55). https://doi.org/10.6017/ihe.2009.55.8424

Daudelin, M. W. (1997). Learning from experience through reflection. Organizational Dynamics, 24(3), 36-48. https://doi.org/10.1016/S0090-2616(96)90004-2

Fraenkel, J. R., Wallen, N. E., \& Hyun, H. H. (1993). How to design and evaluate research in education (Vol. 7). New York, NY: McGraw-Hill.

Guthrie, J. T., Anderson, E., Alao, S., \& Rinehart, J. (1999). Influences of concept-oriented reading instruction on strategy use and conceptual learning from text. The Elementary School Journal, 343-366. https://doi.org/10.1086/461929

Jackson, B. L., \& Kelley, C. (2002). Exceptional and innovative programs in educational leadership. Educational Administration Quarterly, 38(2), 192-212. https://doi.org/10.1177/0013161X02382005

Lin, J. C. G., \& Yi, J. K. (1997). Asian international students' adjustment: Issues and program suggestions. College Student Journal.

Miettinen, R. (2000). The concept of experiential learning and John Dewey's theory of reflective thought and action. International Journal of Lifelong Education, 19(1), 54-72. http://dx.doi.org/10.1080/026013700293458

Popham, W. J. (2000). Modern educational measurement: Practical guidelines for educational leaders. Allyn \& Bacon.

Posner, G. J. (2005). Field experience: A guide to reflective teaching. Allyn \& Bacon.

Smelser, N. J. (2003). On comparative analysis, interdisciplinarity and internationalization in sociology. International Sociology, 18(4), 643-657. https://doi.org/10.1177/0268580903184001

Sternberg, R. J., \& Zhang, L. F. (Eds.). (2014). Perspectives on thinking, learning, and cognitive styles. Routledge.

Taylor, C., \& Albasri, W. (2014). The impact of Saudi Arabia King Abdullah's Scholarship Program in the US. Open Journal of Social Sciences, 2(10), 109. https://doi.org/10.4236/jss.2014.210013

Young, M. (2015). Effective leadership preparation: We know what it looks like and what it can do. Journal of Research on Leadership Education, 10(1), 3-10. https://doi.org/10.1177/1942775115569419 


\section{Appendix A. Survey Questions}

1. Rate the value of your experiential learning, that is, the field experience.

(a) Strongly valuable

(b) Valuable

(c) Indifferent

(d) Not valuable

a. The FE learning allowed me to explore the cross-cultural aspect of education True or False

b. The FE provided additional tools for me to take back to Saudi Arabia that will aid my work as an educational leader

True or False

2. How well did the field experience validate the conceptual learning from the graduate program in a way that transcended the hermeneutic approach to a practitioner approach?

(a) Strongly enlivened my conceptual learning

(b) Enlivened my conceptual learning

(c) Indifferent

(d) Did not validate my conceptual learning

a. FE improved my learning, providing context to the content.

True or false

b. FE provided a practitioner lens in the field of education

True or false

3. Rate the degree to which the field experience relates with areas of academic development in Saudi Arabia.
(a) Strongly related
(b) Related
(c) Indifferent
(d) Has no relation

4. Rate the degree to which field experience relates with leadership.
(a) Strongly related
(b) Related
(c) Indifferent
(d) Has no relation

5. Rate the degree to which you as a student feel prepared for work in academic settings as a result of the field experience.
(a) Very prepared
(b) Prepared
(c) Somewhat prepared
(d) Unprepared 


\section{Appendix B. Demographic Questions}

1. Are you male or female?

2. What is your program of study?

3. How many years of professional experience do you have in a school setting prior to entering into the education graduate program?

a. Where did the previous experience take place?

4. Are you between the ages of $22-28,29-35$, or 36 and above?

\section{Appendix C. Interview Questions}

1. Provide a contextual value of the field experience as you have experienced it.

2. Are you better prepared to serve as an educator, a leader, or both as a result of the field experience?

a. If so, why?

3. Did the field experience provide you with cross-cultural application?

a. If so, what specifically about the field experience gave you a cross-cultural lens that you were able to apply in Saudi Arabia?

4. What would be different for you had you not participated in the field experience

5. Did the field experience helped you apply the concepts, theories, and philosophies of educational and leadership that you were exposed to in the program? 